\title{
A Scientific Hypothesis on the Role of Nutritional Supplements for Effective Management of Hair Loss and Promoting Hair Regrowth
}

\author{
Rajendrasingh Rajput* \\ Hair Transplant Surgeon, Member ISHRS, IAT, \& AHRS India
}

Received: March 28, 2018; Accepted: May 04, 2018; Published: May 11, 2018

*Corresponding author: Rajendrasingh Rajput, Hair Restore, 401 Saffire, 65B, Linking Road, Santacruz west, Mumbai 400054, Tel: +919821308411, E-mail: drrajeshrajput@gmail.com

\begin{abstract}
Our quest for establishing a cause and effect relationship has lead us to accept that only androgens and DHT causes hair loss. However there are various other internal and external factors resulting in hair loss due to dysregulation of the hair growth cycles. There are non hormonal factors that influence and carry out metabolic interactions maintaining a cellular environment to ensure the intricate balance of hair growth cycles. Oxidative stress generated by ROS (Reactive Oxygen Species) from external exposure to pollution, smoking, pesticides in foods, contamination of soil, water, etc. as well as excessive ROS formation due to internal metabolic derangements, can lead to hair loss. Vitamin and mineral deficiencies have been clinically detected in hair loss patients and are known to alter the immune response. Though the prevalence of nutritional deficiencies is common these are covert deficiencies. The nutrient deficiencies cannot always be detected clinically as the deficiencies are masked and compensated by self regulating processes of redistributing the utilization of nutrients in the body, arresting hair growth during stress, sickness, exertion, recovery, etc. which we know as telogen effluvium, and by novel mechanisms like autophagy. In deficiency states body conserves the nutrients by restricting hair growth. It is worthy to note that apparent deficiency of a single nutrient has a cascading effect on optimum utilization of multiple other nutrients and functioning of other body systems. When we desire to stimulate or ensure hair growth it is logical to ensure a supply of building blocks, which are the necessary nutrients, in order to support cell division and growth. We have been investigating hair loss all the time. Let us now change our perspective and direct our efforts on how to strengthen the hair roots to withstand the onslaught of damage and enhance hair growth. In the present review, a low dose comprehensive cyclical nutrient therapy, for hair growth utilized in our practice is included. Here we propose the hypothesis and discuss the scientific basis and mechanism of how to achieve hair growth with the use of nutritional supplements.
\end{abstract}

\section{Introduction}

Common approach of treating any condition by eradicating the cause has lead to a singular ideology of treating hair loss only with DHT (dihydrotestosterone) blockers. Studies reporting benefits of nutritional supplements in hair loss management have dismal support due to the previous scientific belief that DHT and androgens causes hair loss. One is perplexed as to how can nutritional supplements counter DHT and correct hormonal imbalance? Recent scientific evidence confirms that DHT acts by promoting the accumulation of free radicals in androgen sensitive cells which then leads to the release of hair growth inhibiting factor TGF $ß 1$, resulting in hair loss. Direct experimental results show that the accumulation of free radicals or ROS (Reactive Oxygen Species) in response to DHT can be blocked successfully by the use of free radical scavengers, (antioxidants) in androgen sensitive cell cultures [1-5]. There is also more evidence on how nutrients can strengthen the hair roots and promote growth. Let us look at it from a new perspective, with an open mind.

\section{Multiple Factors Other than DHT Can Lead to Hair Loss}

The understanding of hair loss is changing. At present hair loss is agreed to be a multifactorial combination of various intertwined mechanisms [6, 7]. We previously believed that hair loss was genetic, but it can occur without any genetic predisposition or family history [8]. We believed hair loss was caused by androgens, but it is known to occur even if androgen levels are normal and not raised [9-12]. Several research workers have doubted the present theory of androgenetic alopecia and insisted on the need for a better insight into the understanding of the mechanism of hair loss [13-15]. Due to lack of consistent evidence of family history or raised androgens, the condition is no more referred to as androgenic alopecia but now referred to as Male Pattern Hair Loss (MPHL) and Female Pattern Hair Loss (FPHL).

\section{Patterned Hair Loss Reported in Androgen Insensitivity and Hypogonadism}

Cousen and Messenger have reported patterned hair loss in a patient with complete androgen insensitivity syndrome, Orme and Cullen observed it in patients with hypogonadism while Birch and Norwood have recorded patterned hair loss occurring before puberty [16-19]. The clinical observations of these research workers challenge the age old consideration that DHT or androgens are the sole contributing factor to patterned hair loss or androgenic alopecia [16]. There are many predisposing factors other than androgens, which weaken the follicle making 
it sensitive to normal levels of androgens and leading to hair loss. Can correction of these factors and strengthening of the follicles restore hair growth without using anti androgens? We have reviewed and explored this option.

\section{Androgen Levels in Hair Loss Patients a Rarely Raised}

It has been found that raised androgen levels are rarely detected in hair loss patients. Several research workers have now proposed and agreed that not the raised androgens but various factors causing increased sensitivity of the hair follicle cells to normal androgens, leads to poor hair growth and baldness [2022]. Clinically there is another dilemma to deal with. Most people think they are going bald because the hair is falling and insist that the hair fall should stop. But scientifically it is the lack of fallen hair being replaced with new hair or the lack of continuation of hair growth cycles that leads to baldness.

\section{Under Unfavourable Conditions Follicles Remain in Prolonged Resting Phase}

The interruption of hair growth cycles, premature telogen and subsequently the follicles remaining in a continued, prolonged telogen or resting phase, is responsible for gradual progressive thinning and baldness. When the conditions are not favourable or ideal for growth, the hair follicles continue to remain in resting phase and do not come back to the anagen. This new empty follicle stage described as 'kenogen' has been recorded and described by Rebora and Guarrera [23, 24].

Various internal and external factors can make the cellular

Table 1: Some of the factors causing hair loss due to dysregulation of hair cycle or unfavourable conditions for hair growth without any role of DHT

\begin{tabular}{|c|c|}
\hline Internal Factors & External Factors \\
\hline Iron, calcium deficiency & $\begin{array}{l}\text { Smoking, Hookah, Passive } \\
\text { smoking, }\end{array}$ \\
\hline Vit. A, C, E, D deficiency & Tobacco, Pan, Beetle nut, Tea \\
\hline Overuse of Vit. \& Supplements & Alcohol \\
\hline Thyroid hypo or hyper & Hard water areas, \\
\hline Side effect of medications & Stress, Lifestyle, \\
\hline Metabolic disease, diabetes, gout & Lack of sleep, \\
\hline Siborrhoeic scalp & Exposure to excess heat or cold \\
\hline Prolonged illness & Dryness of the Scalp \\
\hline Crash Dieting & Exposure to Dust, Pollution, \\
\hline Poor fluid intake & Continuous Air Conditioning \\
\hline Fat free Diet, & Exposure to chemical fumes \\
\hline High Protein Diet & Mining areas, Construction work \\
\hline Derangement of liver function & Pressurised Airline Cabins \\
\hline Derangement of Kidney function & Over use of Hair Products \\
\hline Post Pregnancy Hair loss & Blow drying \\
\hline
\end{tabular}

environment unfavourable for hair growth. These factors cause an imbalance or dysregulation of the hair growth cycles. Factors causing hair thinning and hair loss without the involvement of the DHT mechanism are listed in table 1. The factors cause non hormonal hair loss. These non hormonal factors are on the rise. These various factors also weaken the hair follicle and affect the dermal papilla cells making them sensitive to normal androgen levels and leading to hair loss [25]. Researchers today agree that, hair loss could be genetic, androgenic, immune mediated, inflammatory, nutritional or due to internal or external factors leading to slowing down and dysregulation of the hair growth cycles [26-28]. We shall try to elaborate on how nutritional support can help in growing more hair and fighting hair loss.

\section{Approach to the Hair Problem}

There are two sides to having good hair. Either reduce the hair loss or promote more hair growth. For the treatment of falling hair you require DHT blockers, anti androgens, anti inflammatory, steroids or other medications. These remedies are not a permanent cure, these are only supportive for better hair growth and need to be continued for a long time. Effective hair growth is seen only as long as these remedies are being used. The moment you discontinue the treatment you begin to suffer hair loss again. Therefore the treatment has to be continued for a very long time, probably lifelong, therefore, increasing the possibility of side effects. There is a need to consider, weather we can achieve hair growth without the use of DHT blockers and offer remedies which are safe for long term use. The parody is that though DHT blockers are recommended for treatment of practically every patient of hair loss, the levels of DHT or other androgens in these patients are rarely found to be raised [26]. The clinical levels of DHT or androgens do not correlate with the grades, severity or the progress of hair loss seen clinically [26].

\section{New Perspective to Strengthen the Follicles and Promote Growth}

Researchers in this field have now concluded that not the raised DHT or androgens but the increased sensitivity of the hair roots is responsible for hair loss [22-24]. We therefore, propose a change of perspective. Instead of fighting the hair loss with long term use of DHT blockers and other medications, having possibility of side effects, why not direct our efforts towards strengthening the hair roots and promoting better growth. Good strong, robust hair roots can stand withstand any cause. At any given time $10-12 \%$ of the hair is in telogen or fall phase and $1 \%$ is in catagen. We are missing the fact that remaining $87-89 \%$ hair which is not in these stages is willing to grow. All this hair needs initiation and propagation of anagen. Hair regrowth can be seen, if we provide stimulation for hair growth, nutritional support and maintain scalp hygiene. We have found this approach to be clinically effective in our practice of hair restoration and we hereby try to share the scientific basis of this therapy.

\section{Oxidative Stress in Hair Loss}

Hair loss is now being seen in younger age groups, which in 
our experience is due to rising competitive life, stress, lack of sleep, exposure to pollution, wrong food choice, erratic lifestyle and some of the additional causes as listed in table 2 . All these causes are a source of generating free radicals or ROS (Reactive Oxygen Species) in the body. The role of ROS and oxidative damage in hair loss was first recognised after detecting raised levels of nitric oxide, lipid peroxidation and glutathione derivatives in hair loss patients [29-32]. These are the markers or indicators of oxidative damage to the cells. Such oxidative damage can be successfully countered by use of free radical scavengers and antioxidants, in order to make the internal environment favourable to achieve hair growth.

\begin{tabular}{|c|c|}
\hline \multicolumn{2}{|c|}{ Table 2: Some of the causes of hair loss seen at early age } \\
\hline No. & Causes \\
\hline 1 & Competitive Lifestyle Stress, lack of sleep, \\
\hline 2 & Lack of sports and good breathing exercise \\
\hline 3 & Poor eating habits - wrong time, wrong choice of food \\
\hline 4 & Gym supplements, Whey Protein, Overuse of Vitamins \\
\hline 5 & Fad Diets - High Protein, No Carbohydrates, Fat free Diet \\
\hline 6 & Restricted eating has become a social practice \\
\hline 7 & Attraction for Sugar foods and processed foods \\
\hline 8 & Increased pollution in air, water and atmosphere \\
\hline 9 & Depleted Ozone layer exposing to UV rays \\
\hline 10 & Hormones, antibiotics, in meat \\
\hline 11 & Fertilizers, insecticides, pesticides, fast growing hybrids \\
\hline 12 & Endocrine Disrupting Chemicals, EDCs in food products \\
\hline
\end{tabular}

\section{Antioxidants Can Counter the Action of DHT}

While working on androgen sensitive cell cultures, Inui, Fukuzato and Itami found that inhibition of hair growth by DHT occurs through release of hair growth inhibiting factor, TGFß1 [33-35]. Interestingly, the research and analysis continued by Hee, Shin, Yoo and Inui into the secretion of TGF $ß 1$ in response to DHT discovered that the effect is mediated through accumulation of ROS or free radicals in androgen sensitive cells [36, 37]. DHT leads to accumulation of ROS in the cells which then leads to the release of TGF $ß 1$. In this experiment it was further discovered that the use of ROS scavengers successfully blocked the release of hair growth inhibiting factor TGF ß1, preventing the inhibition of hair growth $[36,37]$. The work establishes a scientific basis for use of free radical scavengers and anti oxidants instead of anti androgens and enzyme blockers to prevent the action of DHT. From these experiments it can therefore be concluded that accumulation of free radicals has a definitive role in mediating the effect of DHT and use of antioxidants can provide protection to sensitive hair roots from damage inflicted by DHT.

\section{ROS Alters Immune Response and Promotes Inflammation}

The role of immunity and micro inflammation in hair loss has been established through the publications of Trueb and scientific studies by Kubibidila, Yu et al. who have determined the alteration of immunity in malnutrition [38, 39]. Freker and King have recorded the reprogramming of the immune system in zinc deficiency such derangements in immunity can trigger and sustain a continuous mechanisms of hair loss [40].

\section{ROS Bind and Changes Immune Signature of Intracellular Proteins}

Details of another mechanism leading to altered immune response, autoimmune response and propagation of inflammation by ROS have come from the work of Kalkan, Seçkin et al. [41]. Their research has postulated that, after entering inside the cells, the ROS form several covalent bonds by binding and combining with the endogenous, intracellular proteins in the cells. The newly created bonds change the structure of the intracellular proteins. This change in the molecular structure alters the immune recognition pattern of the proteins. As a result the normal proteins are now recognised as new antigens, making them targets of immunity, autoimmune reactions, and inflammation. The altered cell response and metabolism, lead to release of intracellular cytokines, interlukin-1alpha, interlukin1beta, which are known to inhibit hair elongation [34, 35]. This response is the same as which is generated by Monocyte chemo attractant protein-1 (MCP-1) and chemokines which have been identified to be active in hair follicles and sebaceous glands of patients having androgenetic alopecia $[42,43]$. Thus there is another mechanism that supports scientific basis and rationale, for the use of antioxidants to neutralize the ROS in hair loss management. Use of antioxidants and free radical scavengers can prevent a cascade of events and protect the cells from various mechanisms of repeated continuous damage that leads to hair loss [41].

\section{Hair Loss Due to Pollution}

Exposure to free radicals and ROS has now increased through rising air pollution along with contamination of food and water. Sensitive scalp syndrome was defined by Fabio Rinaldi who studied the effects of pollutants on the scalp, and it's relation to hair loss [44]. Philpott demonstrated that pollution increases oxidative stress leading to increased hair shedding, by a mechanism similar androgenic alopecia [25]. The particle size of the pollutants itself triggers oxidative stress in addition to combination of ROS which bind to the particles and reach deeper into the cells. Continued exposure to pollutants, creates chronic low grade inflammation leading to fibrosis and hair loss [45]. Our previous published work has described the mechanism in detail and reported clinical benefit and new hair growth, with use of antioxidants and nutritional supplements in the management of hair loss due to pollution [46]. The study reported reduced itching, dandruff, correction of dryness of scalp, burning and pain in the hair roots by the end of 4 months. While trichoscopy showed 9-12\% improvement in density and $5-7 \%$ improvement in hair calibre [46]. The review of the current research demonstrates that, use of antioxidants can prevent the propagation of inflammation, avoid 
altered immune response, protect the hair follicles from damage, control hair loss and promote hair regrowth [46].

\section{Role of Nutrition in Hair Loss Due to Smoking}

Studies on oxidative stress and smoking by Trueb highlight release of cytokines resulting in micro inflammation, peri follicular fibrosis and hair loss caused by direct pro oxidant effect of smoking [47]. These effects can be successfully countered with the use of antioxidants. Studies by Alberg, Dietrich et al. and Bloomer have confirmed reduced levels of antioxidants in smokers $[46,48,50]$. D'Agostini et al. showed that the effects smoking and cell apoptosis could be treated with supplements of L-cysteine and Vit B6 [51]. Galan et al. found reduced serum concentrations of beta-carotene, vitamins $\mathrm{C}$ and $\mathrm{E}$, zinc and selenium in smokers [52]. The work by all these researchers supports the use of antioxidants, vitamins, minerals and nutritional supplements, in hair loss patients with history of smoking. Though smoking is known to make the follicles sensitive to DHT, the damage cannot be prevented by the use of DHT blockers. As reported in an earlier publication, we have successfully reversed hair loss in smokers and in passive smokers, with the use of low dose antioxidants, nutrients and minerals which strengthen the hair follicles and successfully promote regrowth of the thin, weak, slow growing hair [53]. The study reported $28 \%$ improvement in hair counts, $8 \%$ improvement in hair calibre and with $50 \%$ reduction in villus hair counts within 4 months.

\section{Role of Nutrition in Immunity and Inflammation}

Chronic micro inflammation and altered immune response are an established mechanism of hair loss [38]. Individual studies confirm the importance of antioxidants, vitamins and minerals in maintaining immunity and preventing inflammation. Eugenio Mocchegiani pointed out that micronutrients like zinc, copper and selenium maintain immunity, control inflammation and also preserve antioxidant activity of the cells [54, 55]. Thurnham warns that micronutrients have interactions, with other nutrients, diet, non-nutrients, prescribed medicines, and lifestyle factors like smoking, tea and alcohol, with leading to hair loss [56]. The study emphasises use of nutrient supplements and minerals to maintain immunity and prevent inflammation [56]. The influence of Vitamin C and Vitamin D on immunity, T cells phagocytosis, formation of antibodies, autoimmune response and resistance to infection was reported by Ströhle, Wolters and Hahn $[57,58]$. They also confirmed the importance of micronutrients as essential components of transcription factors, epigenetic modulators, enzymes, cofactors and structural links in antioxidant systems for normal cell functions [57, 58]. Zinc plays an important role in hair growth $[59,60]$. Studies by Freker have noted that zinc deficiency can initiate apoptosis and programmed cell death by inducing secretion of glucocorticoids [61]. Thus there is adequate data to indicate role of nutrients and minerals in maintaining the immune status and preventing micro inflammation which are known mechanisms leading to hair loss.

\section{Role of Vitamins in Hair Growth}

Reichrath, Lehmann, et al. have suggested in their study that, due to the regulatory role of Vitamin A and Vitamin D in epithelial integrity and immunity, these should be considered as hormones [62]. The hair-inductive capacity of dermal papilla cells is directly modulated by Vitamin D3 as proven in the research of Aoi, Inoue, et al. [63]. Vitamin D should therefore form an integral part of all hair growth treatments. Beoy, Woei and Hay reported $34 \%$ improvement in hair counts due to effective inhibition of lipid peroxidation and reduction of oxidative stress from the combined use of tocotrienol and alpha tocopherol [64]. Kwack and Shin reported hair growth and hair elongation by ascorbic acid derivative mediated release of Insulin like Growth Factor, IGF 1 [65]. The scientific facts suggest that providing adequate vitamins and avoiding deficiency states can play a role in preventing hair loss and achieving new hair growth. Table 3 summarises the functional role of individual vitamins, minerals and nutrients which contributes towards better hair growth and helps in hair loss management.

Table 3: Role of various nutrients in hair growth

\begin{tabular}{|c|c|c|}
\hline No & Vitamin Mineral Nutrient & Role through which it benefits Hair growth \\
\hline 1 & Biotin - Vitamin B7 & Hair growth \& Dry skin \\
\hline 2 & Nicotinamide - Vitamin B3 & Anti inflamatory \\
\hline 3 & Cyanocobalamine - Vitamin B12 & Prevents Anemia \\
\hline 4 & Pyridoxin $\mathrm{HCl}$ - Vitamin B6 & Prevents Anemia \& water retention \\
\hline 5 & Vit C & Antioxidant, Collagen synthesis, \\
\hline 6 & Vit A & Antioxidant, \\
\hline 7 & Vit.E & Protects cell membrane from free radicals \\
\hline 8 & Folic acid - B9 & Prevents Anemia, Required for DNA synthesis \\
\hline 9 & Vit D3 & Calcium Metabolism \\
\hline 10 & Tyrosin & Improves Hair growth \\
\hline 12 & L - Ornithine & DNA \& protein synthesis \\
\hline
\end{tabular}




\begin{tabular}{|c|c|c|}
\hline 13 & L - Arginine & Rapid cell division, repair \& endothelial stability \\
\hline 14 & Taurine (2 aminoetahesulphonic acid) & Protects from exercise induced \& other toxicity \\
\hline 15 & Glycine & Precursor to bio synthesis of various proteins \\
\hline 16 & L-Selenomethionine / Sodium Selenate & Rapidly absorbed antioxidant, Elasticity, UV damage\& aging \\
\hline 17 & Sulphur - Methyl sulphonyl methane & Prevents brittle and dry hair \\
\hline 18 & L - Histidine hydrochloride & Protein Metabolism \\
\hline 19 & Ferrous Fumerate & Prevention of Anemia \\
\hline 20 & Calcium D - Pantothenate - B5 & Hair color \& premature aging, CoA \& TCA cycle \\
\hline 21 & Magnesium hydroxide & Calcium, Potassium, Parathyroid \& Insulin Metabolism \\
\hline 22 & Cupric oxide / sulphate & Hair elasticity, pigmentation \& skin tone \\
\hline 23 & $\begin{array}{l}\text { Zinc Gluconate / Zinc sulphate (25mg), } \\
\text { elemental Zinc } 7 \mathrm{mg}\end{array}$ & Cell division, collagen formation \& oxidative damage \\
\hline 24 & Manganese Sulphate & Accelerates hair growth \& prevents UV damage \\
\hline 25 & Iodine & Growth, protein synthesis \& cell metabolism \\
\hline 26 & Molybdenum & Assists use of iron stores, fat burning, \\
\hline 27 & Vanadium Sulphate & Insulin like anabolic, Na \& K transport \\
\hline 28 & Gama Linolenic acid & Anti inflammatory \\
\hline 29 & Chromium Polynicotinate & Cellular metabolism \\
\hline 30 & Para amino benzoic acid & Prevents premature graying of hair \\
\hline 31 & Inositol & Prevents hair thinning \\
\hline 32 & Green Apple Extract - Proanthocyanidin & Flavonoid \& free radical scavenger \\
\hline 33 & Green Tea Extract - Catechins & Antioxidant \& protection from UV damage \\
\hline 34 & Saw Palmeto & Anti androgenic \\
\hline 35 & Co Enzyme Q10 & Rapid energy for growing cells \\
\hline
\end{tabular}

Review of Mineral Analysis Conducted in Hair Loss Patients

Research workers have direct evidence of lower mineral levels in hair loss patients. When compared to healthy men, lower levels of zinc, copper, iron and manganese were found in the hair of patients with male pattern alopecia in the study by Jin, Zhu and Wug [66]. Low BMI and low levels of zinc, copper in hair, serum and urine of Turkish male patients were reported in patients with androgenetic alopecia in their study by Ozturk et, al. [60]. The study also noted that cell division, important cellular and metabolic functions, nucleic acid metabolism, enzymes and coenzymes like collagenase, polymerase, superoxide dismutase, carbonic anhydrase, require zinc, copper, minerals and trace elements to complete their biological functions [60]. Zinc and Copper by themselves have inherent antioxidant activity. Zinc stabilizes cell membrane and prevents oxidative destruction by free radicals [60]. Deshwali et al. in their review mention that zinc has a combined role of action with most of the metabolic enzyme functions. Zinc inhibits miniaturization, follicle regression and promotes hair growth [67]. Zinc deficiency is also associated with hypothyroidism and anaemia which are known causes for hair loss [67]. Skalnaya et al. compared the mineral content of falling hair from frontal area with better growing hair from occipital area and detected lower copper and zinc content in the frontal hair [68]. These research studies have evidence that maintaining mineral balance in the body is essential for good growing hair. Minerals supplements thus have a well defined role in preventing hair loss and inducing regrowth of healthy hair.

\section{The Controversy of Iron Deficiency and Role of Ferritin in Hair Loss}

Deshwali et al. mention that hair follicles are storage sites for ferritin which is utilized in case of deficiency by arresting or compromising the hair growth and maintaining more important functions, as of the blood and bone marrow cells [67]. Which means the iron deficiency in circulation, will get corrected but then there shall be hair loss or telogen effluvium with contradictory lab tests depicting that the iron levels in circulation have been maintained normal despite restricted hair growth. The deficiency being compensated by utilizing iron from the follicles and arresting hair growth is not clinically detectable. Park, $\mathrm{Na}$, et al. reviewed the role of iron deficiency and found it had a significant role in hair loss [69]. Research by Ruston et al., Moeinvaziri et al., Kantor, Kessler et al., and Deloche, Bastien et al., have found correlation between iron deficiency and hair loss [70-73]. Whereas Sinclair, Bregy, Trueb et al., and Olsen, who studied serum Ferritin as the representative of iron stores in the body, have found no relation between iron deficiency and hair loss [74-76]. The contrasting 
findings were criticized by Ruston, Bergfeld et al. it is important to know about nutrient interactions to decipher the controversial findings [77]. The fact is that iron deficiency would be masked as hair growth is arrested, follicles are shifted to telogen and ferritin stores in the follicle are utilized to compensate low ferritin levels [67]. Thus clinically serum ferritin levels continue to appear as normal.

At times normal serum ferritin may not be biologically utilized due to other coexisting deficiencies. Thakachan et al. and Diaz et al. have impressed the role of vitamin $C$ in absorption and utilization of iron $[78,79]$. Deshwali et al. have reviewed the importance of copper in formation of haemoglobin and providing the oxygen carrying capacity to the RBCs [67]. Mejia, Chew and García-Casal et al. have determined the role of combined supplementation of vitamin A and beta carotene which, aid in iron absorption [80,81] Studies by Semba, Bloem et al, and Suharno, West et al. have found that vitamin $\mathrm{A}$ is also required for mobilizing the stored iron to the sites of generation of Red Blood Cells (RBC) and formation of haemoglobin [82, 83]. Importance of zinc for erythropoiesis has been stressed by Kelkitli, Ozturk et al. [84]. Optimum functioning of nutrients is interrelated. A balance of all nutrients is required to ensure the effective utilization of iron [85]. Therefore patients with normal values of storage iron represented by serum ferritin can have coexisting deficiencies of vitamin A, vitamin C, zinc or copper, leading to poor incorporation of iron into RBC or reduced oxygen carrying capacity, resulting in hair loss, despite apparent normal iron ferritin, storage levels making us conclude there is no relation between serum iron and hair loss. Iron levels are essential for good hair growth and require to be corrected with a balance of other associated vitamins, minerals and nutrients without excess of any. We can conclude that a balance of micro nutrients and vitamins is required to achieve the required metabolic functions in the body. Individual single nutrient replacements could be ineffective and individual deficiencies detected may not provide a correct interpretation of the nutritional balance of the homeostasis or internal environment.

\section{Multiple Deficiencies}

A deficiency may manifest as a single nutrient but these are often, associated with other, covert or subclinical deficiencies. Single nutrient replacement never works. You need to replace a combined set of nutrients which will help each other work better. Zimmermann and Hess have described the details of various ways in which iron deficiency and availability of micronutrients, affects thyroid function [86, 87]. The role of calorie restriction, low intake of fatty acids, crash dieting, starvation, zinc and iron deficiency in diffuse hair loss has been emphasised by Harrison and Bergfeld [88]. Though thyroid hormone is made up of tyrosine and iodine, other nutrients are also required to support the conjugation and creation of the hormone. Iron has a role in conversion of storage form of thyroid hormone T4 to the active form T3. The above mentioned studies and the report by Betsy, Binitha and Sarita highlight the association between zinc, copper, selenium deficiencies and altered thyroid function leading to hair loss [89]. A study of hair loss after Bariatric Surgery by Rojas and Gosch detected lower hair loss in patients who maintained zinc, iron, copper, selenium levels [90]. All these studies establish a direct role of micronutrients, vitamins, minerals in hair loss management. Thus comprehensive overall, nutritional correction is essential in order to preserve hair quality, prevent hair loss and promote healthy hair growth.

\section{Nutritional Deficiencies are clinically Difficult to Detect in Hair Loss Patients}

Patients continue to lose hair despite clinical tests being normal making it very difficult to convincingly determine a cause and effect relationship. Let us examine why it is difficult to detect existing nutrient deficiencies in hair loss patients? First important research that explains the masking or compensation of nutrient deficiencies by replacing them, is autophagy. The work on autophagy by Yoshinori Oshumi of Japan received the 2016 Nobel Prize for Medicine. The research shows that under conditions of starvation, malnutrition and calorie restriction, there is a programmed breakdown of intracellular organelles in order to retrieve the required nutrients which are found to be deficient. The process is termed as autophagy. The nutrients retrieved by autophagy are provide to maintain normal body functions and restore normal levels in circulation $[91,92]$. Similar mechanism with respect to hair growth is being arrested and ferritin being utilized for more indispensible body functions has been also described by Deshwali , et al. [67]. Thus we find normal circulating levels of nutrients in the blood making the nutrient deficiencies undetectable. The deficiencies are auto corrected, compensated and masked by redistribution of priorities and by mechanism of autophagy. Therefore deficiencies cannot be detected on laboratory tests. The moment you begin low dose supplement support the patient responds with hair growth within 2-3 months. Clinically we should not wait to detect deficiencies but start low dose nutritional support for patients who suffer from hair loss. Correlating these nutritional priority theories clinically with hair loss cycles, we do find that telogen effluvium is triggered whenever there is higher demand from other body systems. High fever, illness, mental trauma, stress, recovery from surgery, extreme climatic changes, intestinal problems, crash dieting all lead to acute telogen which shuts off hair growth under unfavourable conditions. Hair growth may spontaneously resume when the conditions are corrected or may continue until the nutritional and functional balance of the body is restored.

\section{Subclinical and Covert Deficiencies}

Another status of nutritional deficiencies described by nutritional research is subclinical or covert deficiencies. These deficiencies are hidden and may not manifest unless there is increased demand from sickness, stress or events like wound healing. The patients are apparently healthy and the deficiencies are not clinically detectable. In such a state the body metabolism is regulated, reset and adapted to continue functioning with low levels of nutrients. The prevalence of such hidden deficiencies is much higher than we can realise $[93,94]$. The role of subclinical 
dietary deficiencies in non scarring hair loss was enlisted twenty three years ago by Dawyer in a publication in the year 1994 [95]. Dry skin, hair breakage, pain in the hair roots, flaky scalp, generalized thinning of hair, loss of shine, bounce, lustre in the hair, may be partial presentations of developing alopecia and may represent, uncorrected subclinical deficiencies. Covert deficiency of one nutrient can lead to inadequate functioning of a number of other nutrients. Cellular metabolism is inter linked. Subclinical deficiency of nutrients is found to affect the entire thyroid pituitary axis [96]. Iodine deficiency is a known cause of hypothyroidism leading to hair loss. However, subclinical deficiencies of vitamin A, vitamin D, iron and selenium also lead to poor functioning of the thyroid gland and require concomitant correction [97-100].

More than one subclinical deficiencies may exist in an apparently healthy person. Clinically we may not be able to detect single or multiple nutrient deficiencies. Therefore, a single nutrient support for hair loss may be inadequate; we need to provide a balance of various essential nutrients to ensure better functioning of the body systems which would then ensure good hair growth.

\section{Comprehensive Low Dose Nutrient Therapy}

Nutritional deficiencies are on the rise. Supplements are required for normal healthy living. Inter nutrient reactions can reduce the absorption and efficiency when multiple nutrients are administered together. Manifestation of a single nutrient deficiency is a sign of other associated subclinical deficiencies. A comprehensive balanced use of supplements is required to ensure synergistic action and prevent overdose. Whereas, it is customary to advice nutritional supplements as regular daily doses all throughout seven days a week, we have adopted a program of using each supplement once in three days which translates to twice a week instead of the common trend of daily dosage. The approach allows the inclusion of more number of different supplements in the comprehensive program, while restricting the total dose of individual supplements to remain much below the safe limits and avoid the possibility of an overdose. One such combination used in our clinic for hair growth is presented in table 4. Use of ten nutrients is distributed over three days in a repeating cycle. The approach has been found to be beneficial in hair loss management and achieving new hair growth in various indications $[46,53$, 101-105]. A clinical trial with 100 patients in each group, having a control group and treatment group comparing $2 \%$ minoxidil plus finasteride in men and only $2 \%$ minoxidil in women has been published earlier [106]. The density and calibre were measured by tattooed, computerized trichoscopy analysis. The average improvement in density was $18 \%$ at 2 months and $30 \%$ and at 4 months. The average improvement in calibre in 2 months was $9 \%$ and at 4 months was $21 \%$. Hair loss was controlled in all the patients in treatment group, within 4-6 weeks. A photographic representation of these male and female results is included in this review. Figure 1a, 1b show improvement after four months of low dose once in three days, in a case of grade III hereditary hair loss in a male patient which has reversed to grade II, without the use of minoxidil or finasteride. While figure $2 \mathrm{a}, 2 \mathrm{~b}$ show a result of similar therapy for four months in grade II female pattern hair loss which has reversed to grade I.

Table 4: Cyclical Nutrient Therapy two supplement per day in a 3 - day Cycles

\begin{tabular}{|c|c|}
\hline Monday \& Thursday & Antioxidant, Calcium, Vitamin D3 \\
\hline Tuesday \& Friday & Iron, Folic Acid, Vitamin C, Omega 3 \\
\hline Wednesday \& Saturday & Essential Aminoacids, B-Complex, Biotin \\
\hline Sunday - no medicines & $\begin{array}{c}\text { Detox on Sunday OR add extra a dose of } \\
\text { another nutrient as per individual status } \\
\text { if required }\end{array}$ \\
\hline
\end{tabular}

Provides ten different nutrient combinations that are synergistic with each other over three days preventing overdose and inter nutrient interaction.

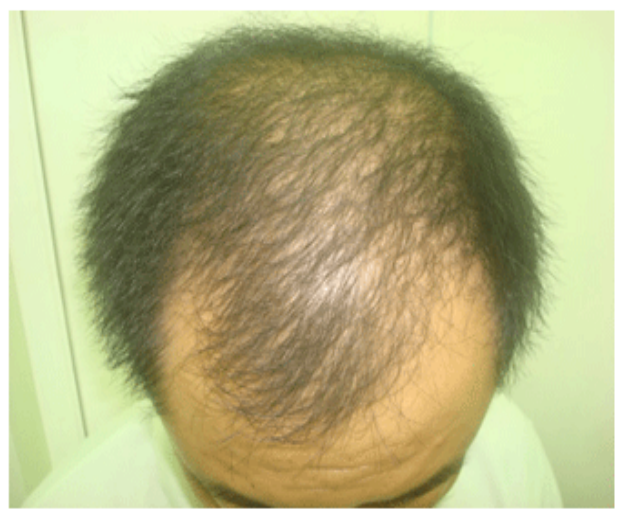

Figure 1a: Hereditary hair loss in a male patient

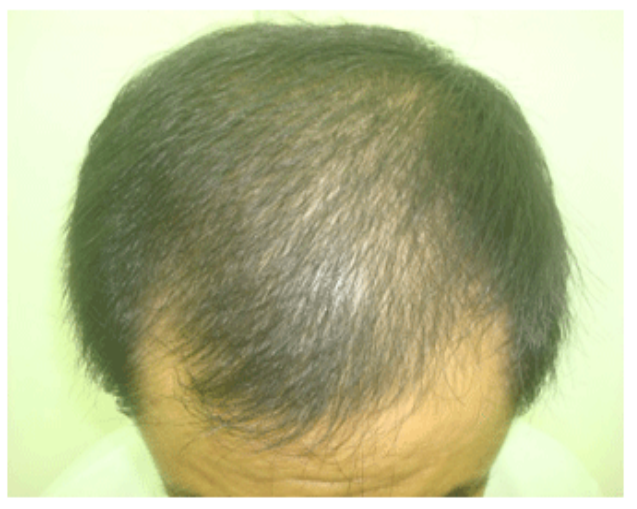

Figure 1b: Improvement in hair quality, density and calibre after 4 months of nutritional therapy 


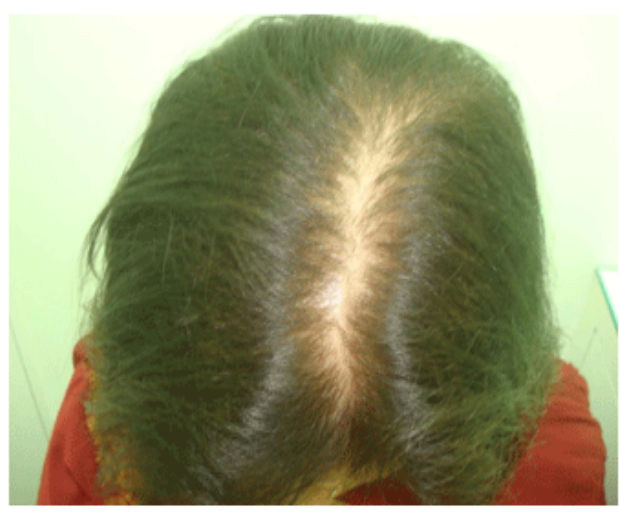

Figure 2a: Female pattern hair loss

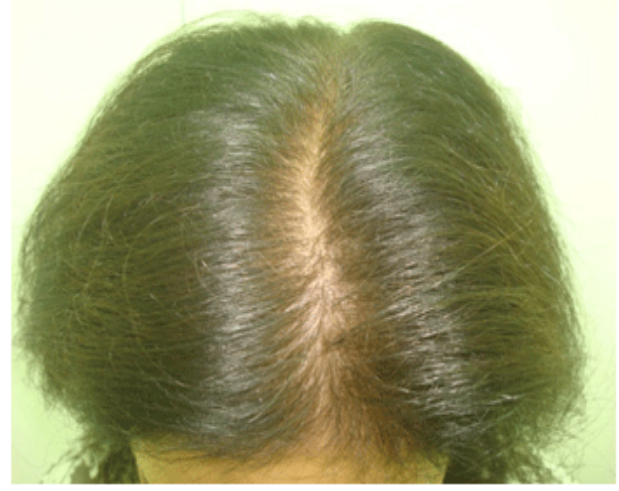

Figure 2b: Improvement in hair quality, density and calibre after 4 months of nutritional therapy

\section{Conclusion}

Anti androgens is not the only basis of treating hair loss. Weak hair roots become sensitive and susceptible to multiple factors. Whereas, strong hair roots can stand for any cause. Hair loss is multifactorial. Nobody goes bald due to hair fall, people go bald as fallen hair is not replaced with new hair, because the hair growth cycles are disrupted or discontinued. Instead of fighting hair loss with medications which have possibility of side effects, we can change our perspective to strengthening the hair roots and promoting better hair growth. Research shows that altered immunity, inflammation, hormonal imbalance and dysregulation of hair growth cycles can be improved with nutritional support. There is evidence that the action of DHT is mediated through ROS and can be successfully blocked with antioxidants. Low mineral levels have been clinically detected to be associated with hair loss and require correction. Nutrient deficiencies may not always be clinically detectable due to compensation by autophagy and presence of subclinical covert deficiencies. A single deficiency often is a representative of several underlying deficiencies, interlinked with derangement of numerous cellular functions at multiple levels. A corrective balance of multiple nutrients requires to be provided in order to ensure consistent results. The nutritional support also has to continue for a long time to maintain active hair growth. A comprehensive correction of nutrients without utilizing any single nutrient in excess is recommended as a low dose once in three days cycle. The approach has been successfully utilized to achieve hair growth for various indications without the use of anti androgens, DHT blockers or Finasteride.

\section{References}

1. Inui S, Fukuzato Y, Nakajima T, Yoshikawa K, Itami S. Androgeninducible TGF-beta1 from balding dermal papilla cells inhibits epithelial cell growth: a clue to understand paradoxical effects of androgen on human hair growth. FASEB J. 2002;16(14):1967-1969.

2. Inui S, Fukuzato Y, Nakajima T Yoshikawa K, Itami S. Identification of and rogen-inducible TGF-beta1 derived from dermal papilla cells as a key mediator in androgenetic alopecia. J Investig Dermatol Symp Proc. 2003;8(1):69-71.

3. Itami S. Pathomechanism of androgenetic alopecia and new treatment. Article in Japanese, Nihon Ronen Igakkai Zasshi. 2004;41(6):598-600. doi: 10.3143/geriatrics.41.598

4. Hee Chul E. The involvement of ROS on androgen inducible TGF beta 1 regulation derived from dermal papilla cells; a suggestive implication of ROS on androgenetic alopecia. Journal of the American Academy of Dermatology. 2008;58(2):AB84. Suppl 2.

5. Shin H, Yoo H G, Inui S, Itami S, Kim I G, A-Ri Cho,et.al. Induction of transforming growth factor-beta 1 by androgen is mediated by reactive oxygen species in hair follicle dermal papilla cells. BMB Rep. 2013;46(9):460-464. doi: 10.5483/BMBRep.2013.46.9.228

6. Wolff H, FischerTW,Blume-Peytavi U. The Diagnosis and Treatment of Hair and Scalp Diseases. Dtsch Arztebl Int. 2016;113(21): 377386. doi: 10.3238/arztebl.2016.0377

7. Trueb R M, Pharmacologic interventions in aging hair. Clinical Interventions in Aging. 2006:1(2);121-129.

8. Lee W-S, Lee H-J. Characteristics of Androgenetic Alopecia in Asian. Ann Dermatol. 2012;24(3):243-252. doi:10.5021/ ad.2012.24.3.243

9. Cranwell W, Sinclair R. Male Androgenetic Alopecia. In:De Groot LJ, Chrousos G, Dungan K, et al., editors. Endotext. South Dartmouth (MA): MDText.com, Inc.; 2000

10. Pitts R L. Serum elevation of dehydroepiandrosterone sulfate associated with male pattern baldness in young men. Journal of the American Academy of Dermatology. 1987;16(3):571-573.

11. Schmidt J B. Hormonal basis of male and female androgenic alopecia: clinical relevance. Skin pharmacology : the official journal of the Skin Pharmacology Society. 1994;7:61-66.

12. Schmidt J B, Lindmaier A, Trenz A, Schurz B, Spona J. Hormone studies in females with androgenic hairloss. Gynecologic and obstetric investigation. 1991;31(4):235-239.

13. Dawber R P. Aetiology and pathophysiology of hair loss. Dermatologica. 1987;175 Suppl 2:23-28.

14. Jahoda C A. Cellular and developmental aspects of androgenetic alopecia. Exp Dermatol. 1998 ;7(5):235-48.

15. Ellis J A, Sinclair R, Harrap S B. Androgenetic alopecia: pathogenesis and potential for therapy. Expert Rev Mol Med. 2002:4(22):1-11.

16. Cousen P, Messenger A. Female pattern hair loss in complete 
androgen insensitivity syndrome. Br J Dermatol. 2010; 162(5):1135-1137. doi: 10.1111/j.1365-2133.2010.09661.x

17. Orme S, Cullen DR, Messenger AG. Diffuse female hair loss: are androgens necessary?. Br J Dermatol. 1999;141(3):521-523.

18. Birch MP, Messenger JF, Messenger AG. Hair density, hair diameter and the prevalence of female pattern hair loss. Br J Dermatol. 2001;144(2):297-304.

19. Norwood OT. Incidence of female androgenetic alopecia (female pattern alopecia). Dermatol Surg. 2001;27(1):53-54.

20. Ustuner ET. Cause of Androgenic Alopecia: Crux of the Matter. Plast Reconstr Surg Glob Open. 2013;1(7):e64. doi: 10.1097/ GOX.0000000000000005

21. Kaufman KD. Androgens and alopecia. Mol Cell Endocrinol. 2002;198(1-2):89-95.

22. Sawaya ME, Price VH. Different levels of 5alpha-reductase type I and II, aromatase, and androgen receptor in hair follicles of woman and men with androgenetic alopecia. J Invest Dermatol.1997;109(3):296-300.

23. Rebora A, Guarrera M. Kenogen. A new phase of hair cycle. Dermatology. 2002;205(2):108-110.

24. Guarrera M, Rebora A. Kenogen in female androgenetic alopecia. A longitudinal study. Dermatology. 2005;210(1):18-20.

25. Philpott MP, Farjo N , Farjo B, Bahta AW. Premature senescence of balding dermal papilla cells in vitro is associated with p16 (INK4a) expression. J Invest Dermatol. 2008;128(5):1088-1094.

26. Urysiak-Czubatka, Kmieć ML, Broniarczyk-Dyła G. Assessment of the usefulness of dihydrotestosterone in the diagnostics of patients with androgenetic alopecia. Postepy Dermatol Alergol. 2014;31(4):207-215. doi: 10.5114/pdia.2014.40925

27. Headington JT. Telogen effluvium: new concepts and review. Arch Dermatol. 1993;129(3):356-363.

28. Kligman AM. Pathologic dynamics of human hair loss. I. Telogen effluvium. Arch Dermatol. 1961;83:175-198.

29. Giralt M, Cervello I, Nogues MR, Puerto AM, Ortin F, Argany $\mathrm{N}$, et al. Glutathione, glutathione S-transferase and reactive oxygen species of human scalp sebaceous glands in male pattern baldness. J Invest Dermatol. 1996;107(2):154-158.

30. Naziroglu M, Kokcam I. Antioxidants and lipid peroxidation status in the blood of patients with alopecia. Cell Biochem Funct. 2000;18(3):169-173.

31. Akar A, Arca E, Erbil H, Akay C, Sayal A, Gur AR. Antioxidant enzymes and lipid peroxidation in the scalp of patients with alopecia areata. J Dermatol Sci. 2002;29(2):85-90.

32. Koca R, Armutcu F, Altinyazar H, Gurel A. Evaluation of lipid peroxidation, oxidant/antioxidant status and serum nitric oxide levels in alopecia areata. Med Sci Monit. 2005;11(6):296-299.

33. Inui S, Fukuzato Y, Nakajima T, Yoshikawa K, Itami S. Androgeninducible TGF-beta1 from balding dermal papilla cells inhibits epithelial cell growth: a clue to understand paradoxical effects of androgen on human hair growth. FASEB J. 2002;16(14):1967-1969.

34. Inui S, Fukuzato Y, Nakajima T, Yoshikawa K, Itami S. Identification of androgen-inducible TGF-beta1 derived from dermal papilla cells as a key mediator in androgenetic alopecia. J Investig Dermatol Symp Proc. 2003;8(1):69-71.
35. Itami S. Pathomechanism of androgenetic alopecia and new treatment. Nihon Ronen Igakkai Zasshi. 2004;41(6):598-600.

36. Hee CE. The involvement of ROS on androgen inducible TGF beta 1 regulation derived from dermal papilla cells; a suggestive implication of ROS on androgenetic alopecia. Journal of the American Academy of Dermatology. 2008;58(2):AB84.

37. Shin $\mathrm{H}$, Yoo $\mathrm{HG}$, Inui $\mathrm{S}$, Itami $\mathrm{S}$, et.al. Induction of transforming growth factor-beta 1 by androgen is mediated by reactive oxygen species in hair follicle dermal papilla cells. BMB Rep. 2013;46(9):460-464.

38. Trüeb RM. Molecular mechanisms of androgenetic alopecia. Exp Gerontol. 2002;37(8-9):981-990.

39. Kubibidila S, Yu L, Ode D, Warrier RP. The immune response in protein-energy malnutrition and single nutrient deficiencies. 1993;8;121-155. Plenum Press, New York, NY.

40. Fraker PJ, King LE. Reprogramming of the immune system during zinc deficiency. Ann Rev Nutr. 2004;24: 277-298.

41. Kalkan G, Seçkin HY, Benli, et al. Relationship between manganese superoxide dismutase (MnSODAla-9Val) and glutathione peroxidase (GPx1 Pro $197 \mathrm{Leu}$ ) gene polymorphisms and alopecia areata. Int J Clin Exp Med. 2015;8(11):21533-21540.

42. Mahe YF, Michelet JF, Billoni N, et al. Androgenetic Alopecia and microinflammation. Int J Dermatol. 2000;39(8): 576-584.

43. Smith RS, Smith TJ, Bleden TM, et al. Fibroblasts as sentinel cells. Synthesis of chemokines and regulation of inflammation. Am J Pathol. 1997;151(2): 317-322.

44. Rinaldi F. Pollution, scalp and hair transplant. Hair Transplant Forum Int. 2008;18:227.

45. Vierkötter A, Schikowski T, Ranft U, Sugiri D, Matsui M, Krämer U, et al. Airborne Particle Exposure and Extrinsic Skin Aging. J Invest Dermatol. 2010;130(12):2719-2726. doi: 10.1038/jid.2010.204

46. Rajput R. Understanding Hair Loss due to Air Pollution and the Approach to Management. Hair Ther Transplant. 2015;5:133. doi:10.4172/21670951.1000133

47. Trüeb RM. Association between smoking and hair loss: Another opportunity for health education against smoking? Dermatology. 2003;206(3):189-191.

48. Alberg AJ, Chen JC, Zhao H, Hoffman SC, Comstock GW, Helzlsouer $\mathrm{KJ}$. Household exposure to passive cigarette smoking and serum micronutrient concentrations. Am J Clin Nutr. 2000;72(6):15761582.

49. Alberg A. The influence of cigarette smoking on circulating concentrations of antioxidant micronutrients. Toxicology. 2002;15;180(2):121-137.

50. Bloomer RJ. Decreased blood antioxidant capacity and increased lipid peroxidation in young cigarette smokers compared to nonsmokers: Impact of dietary intake. Nutr J. 2007;6:39. doi: 10.1186/1475-2891-6-39

51. D’Agostini F, Fiallo P, Pennisi TM, De Flora S. Chemoprevention of smoke-induced alopecia in mice by oral administration of L-cystine and vitamin B6. J Dermatol Sci. 2007;46(3):189-198.

52. Galan P, Viteri FE, Bertrais S, Czernichow S, Faure H, Arnaud J, et al. Serum concentrations of beta-carotene, vitamins $\mathrm{C}$ and $\mathrm{E}$, zinc and selenium are influenced by sex, age, diet, smoking status, alcohol 
consumption and corpulence in a general French adult population. Eur J Clin Nutr. 2005;59(10):1181-1190.

53. Rajput RS. Benefit from Vitamin Therapy in Smoker's Hair. Hair Ther Transplant. 2016;6:141. doi: 10.4172/2167-0951.1000141

54. Eugenio Mocchegiani, Laura Costarelli, Robertina Giacconi, Francesco Piacenza, Andrea Basso, Marco Malavolta. Micronutrient $(\mathrm{Zn}, \mathrm{Cu}, \mathrm{Fe})$-gene interactions in ageing and inflammatory agerelated diseases: Implications for treatments. Ageing Res Rev. 2019;11(2):297- 319. doi: 10.1016/j.arr.2012.01.004

55. Mocchegiani E, Costarelli L, Giacconi R, Malavolta M, Basso A, Piacenza F, et al. Micronutrient-gene interactions related to inflammatory/immune response and antioxidant activity in ageing and inflammation. A systematic review. Mech Ageing Dev. 2014;136-137:29-49. doi: 10.1016/j.mad.2013.12.007

56. Thurnham DI. An overview of interactions between micronutrients and of micronutrients with drugs, genes and immune mechanisms. Nutr Res Rev. 2004;17(2):211-240. doi: 10.1079/NRR200486

57. Ströhle A, Wolters M, Hahn A. Micronutrients at the interface between inflammation and infection--ascorbic acid and calciferol: part 1, general overview with a focus on ascorbic acid. Inflamm Allergy Drug Targets. 2011;10(1):54-63.

58. Ströhle A, Wolters M, Hahn A. Micronutrients at the interface between inflammation and infection--ascorbic acid and calciferol. Part 2: calciferol and the significance of nutrient supplements. Inflamm Allergy Drug Targets. 2011;10(1):64-74.

59. Betsy A, Binitha M, Sarita S. Zinc Deficiency Associated with Hypothyroidism: An Overlooked Cause of Severe Alopecia. Int J Trichology. 2013;5(1):40-42. doi: 10.4103/0974-7753.114714

60. Ozturk P, Kurutas E, Ataseven A, Dokur N, Gumusalan Y, Gorur A, et al. BMI and levels of zinc, copper in hair, serum and urine of Turkish male patients with androgenetic alopecia. J Trace Elem Med Biol. 2014;28(3):266-270. doi: 10.1016/j.jtemb.2014.03.003

61. Fraker Pamela J. Roles for Cell Death in Zinc Deficiency. J Nutr. 2005;135(3):359-362.

62. Reichrath J, Lehmann B, et al. Vitamins as hormones. Horm Metab Res. 2007;39(2):71-84.

63. Aoi $\mathrm{N}$, Inoue $\mathrm{K}$, Chikanishi $\mathrm{T}$, et al. $1 \alpha, 25$-dihydroxyvitamin D3 modulates the hair-inductive capacity of dermal papilla cells: therapeutic potential for hair regeneration. Stem Cells Transl Med. 2012;1(8):615-626. doi: 10.5966/sctm.2012-0032

64. Beoy LA, Woei WJ, Hay YK. Effects of Tocotrienol Supplementation on Hair Growth in Human Volunteers. Trop Life Sci Res. 2010;21(2):91-99.

65. Kwack MH, Shin SH, Kim SR, Im SU, Han IS, Kim MK, et al. 1-Ascorbic acid 2-phosphate promotes elongation of hair shafts via the secretion of insulin-like growth factor-1 from dermal papilla cells through phosphatidylinositol 3-kinase. Br J Dermatol. 2009;160(6):1157-1162. doi: 10.1111/j.13652133.2009.09108.x

66. Jin W, Zhu Z, Wu S, Zhang X, Zhou X. Determination of zinc, copper, iron and manganese contents in hair for MPA patients and healthy men. Guang Pu Xue Yu Guang Pu Fen Xi. 1998;18(1):91-93.

67. Deshwali S, Kare PK, Agrawal BK, Alex A. Study of serum zinc, copper and ferritin levels in alopecia patients. Int J Adv Res Biol.
Sci. 2015;2(7): 94-96.

68. Skalnaya MG, Tkachev VP. Trace elements content and hormonal profiles in women with androgenetic alopecia. J Trace Elem Med Biol. 2011;25:50-53. doi: 10.1016/j.jtemb.2010.10.006

69. Park SY, Na SY, Kim JH, Cho S, Lee JH. Iron Plays a Certain Role in Patterned Hair Loss. J Korean Med Sci. 2013;28(6):934-938.

70. Rushton DH, Norris MJ, Dover R, Busuttil N. Causes of hair loss and the developments in hair rejuvenation. Int J Cosmet Sci. 2002;24(1):17-23. doi: 10.1046/j.0412-5463.2001.00110.x

71. Moeinvaziri M, Mansoori P, Holakooee K, Safaee Naraghi Z, Abbasi A. Iron status in diffuse telogen hair loss among women. Acta Dermatovenerol Croat. 2009;17(4):279-284.

72. Kantor J, Kessler LJ, Brooks DG, Cotsarelis G. Decreased serum ferritin is associated with alopecia in women. J Invest Dermatol. 2003;121(5):985-988.

73. Deloche C, Bastien P, Chadoutaud S, Galan P, Bertrais S, Hercberg $\mathrm{S}$, et al. Low iron stores: a risk factor for excessive hair loss in nonmenopausal women. Eur J Dermatol. 2007;17(6):507-512.

74. Sinclair R. There is no clear association between low serum ferritin and chronic diffuse telogen hair loss. Br J Dermatol. 2002;147(5):982-984.

75. Bregy A, Trueb RM. No association between serum ferritin levels $>10$ microg/l and hair loss activity in women. Dermatology. 2008;217(1):1-6. doi: 10.1159/000118505

76. Olsen EA, Reed KB, Cacchio PB, Caudill L. Iron deficiency in female pattern hair loss, chronic telogen effluvium, and control groups. J Am Acad Dermatol. 2010;63(6):991-999. doi: 10.1016/j. jaad.2009.12.006

77. Rushton DH, Bergfeld WF, Gilkes JJ, Van Neste D. Iron deficiency and hair loss: nothing new? J Am Acad Dermatol. 2011;65(1):203204. doi: 10.1016/j.jaad.2011.02.020

78. Thankachan P, Walczyk T, Muthayya S, Kurpad AV, Hurrell RF. Iron absorption in young Indian women: the interaction of iron status with the influence of tea and ascorbic acid. Am J Clin Nutr. 2008; 87(4):881-886.

79. DiazM, Rosado JL, Allen LH, Abrams S, Garcia OP. The efficacy of a local ascorbic acid-rich food in improving iron absorption from Mexican diets: a field study using stable isotopes. Am J Clin Nutr. 2003;78(3):436-440.

80. Mejia, LA, Chew V. Hematological effect of supplementing iron with results of Mejia (1986), who demonstrated interactions bevitamin A alone and in combination with iron. Am J Clin Nutr. 1988;48:595-600.

81. García-Casal MN, Layrisse M, Solano L, et al. Vitamin A b -carotene can improve nonheme iron absorption from rice wheat and corn by humans. J Nutr. 1998;28:646-650.

82. Semba RD, Bloem MW. The anemia of vitamin A deficiency: epidemiology and pathogenesis. Eur J Clin Nutr. 2002;56(4):271281.

83. Suharno D, West CE, Muhilal, Karyadi D, Hautvast JG. Supplementation with vitamin A and iron for nutritional anaemia in pregnant women in West Java, Indonesia. Lancet. 1993;342(8883):1325-1328. 
84. Kelkitli E, Ozturk N, Aslan NA. Serum zinc levels in patients with iron deficiency anemia and its association with symptoms of iron deficiency anemia. Ann Hematol. 2016;95(5):751-756. doi: 10.1007/s00277-016-2628-8

85. Lynch SR. Interaction of iron with other nutrients. Nutr Rev. 1997;55(4):102-110.

86. Zimmermann MB. The influence of iron status on iodine utilization and thyroid function. Annu Rev Nutr. 2006;26:367-389. doi: 10.1146/annurev.nutr.26.061505.111236

87. Hess SY. The impact of common micronutrient deficiencies on iodine and thyroid metabolism: the evidence from human studies. Best Pract Res Clin Endocrinol Metab. 2010;24(1):117-132. doi: 10.1016/j.beem.2009.08.012

88. S Harrison, W Bergfeld. Diffuse hair loss: Its triggers and management. Cleveland Clinic Journal of Medicine. 2009;76(6): 361-367. doi: 10.3949/ccjm.76a.08080

89. Betsy A, Binitha M, Sarita S. Zinc Deficiency Associated with Hypothyroidism: An Overlooked Cause of Severe Alopecia. International Journal of Trichology. 2013;5(1):40-42. doi: 10.4103/0974-7753.114714

90. Rojas P, Gosch M, Basfi-Fer K, Carrasco F, Codoceo J, Inostroza $\mathrm{J}$, et al. Alopecia in women with severe and morbid obesity who undergo bariatric surgery. Nutr Hosp. 2011;26(4):856-862. doi: 10.3305/nh.2011.26.4.5199

91. Guimaraes C. and Linden R. Programmed cell deaths. Apoptosis and alternate deathstyles. Eur J Biochem. 2004;271(9):16381650. doi: 10.1111/j.1432-1033.2004.04084.x

92. Yoshimori, T. Autophagy: A regulated bulk degradation process inside cells. Biochem Biophys Res Commun. 2004;313(2): 453458.

93. Bender AE. Subclinical and covert malnutrition. Bull Schweiz Akad Med Wiss. 1976;31(4-6):279-290.

94. Bailey RL, West Jr KP, Black RE. The Epidemiology of Global Micronutrient Deficiencies. Ann Nutr Metab. 2015;66(suppl 2):2233. doi: 10.1159/000371618

95. Dwyer JT. Vegetarian eating patterns: Science, values, and food choices -- Where do we go from here?. Am J Clin Nutr. 1994;59(5 Suppl): 1255S-1262S.
96. Zimmermann MB. Interactions of vitamin $A$ and iodine deficiencies: effects on the pituitary-thyroid axis. Int J Vitam Nutr Res. 2007;77(3):236-240. doi: 10.1024/0300-9831.77.3.236

97. El-Eshmawy MM, Arafa MM, Elzehery RR, Elhelaly RM, Elrakhawy MM, El-Baiomy AA. Relationship between vitamin A deficiency and the thyroid axis in clinically stable patients with liver cirrhosis related to hepatitis C virus. Appl Physiol Nutr Metab. 2016;41(9):985-991. doi: 10.1139/apnm-2016-0056.

98. Yilmaz H, Cakmak M, Darcin T, Inan O, Gurel OM, Bilgic MA, Bavbek $\mathrm{N}$, Akcay A. Subclinical hypothyroidism in combination with vitamin D deficiency increases the risk of impaired left ventricular diastolic function. Endocr Regul. 2015;49(2):84-90.

99. Chanoine JP. Selenium and thyroid function in infants, children and adolescents. Bio factors. 2003;19(3-4):137-143.

100. Ravanbod M, Asadipooya K, Kalantarhormozi M, Nabipour I, Omrani GR. Treatment of iron-deficiency anemia in patients with subclinical hypothyroidism. Am J Med. 2013;126(5):420424. doi: 10.1016/j.amjmed.2012.12.009

101. Rajput RJ. Cyclical Medicine for Hair loss Management and Improving Results in Hair Transplantation. Hair Transplant Forum International. 2008;18:208.

102. Rajput RJ. Is there a Role for Adjuvants in the Management of Male pattern hair loss? Published in Journal of Cutaneous and Aesthetic Surgery. 2010;3(2): 82-86. doi: 10.4103/0974-2077.69016

103. Rajendrasingh JR. Role of Non Androgenic Factors in Hair loss and Hair Regrowth. J Cosmo Trichol. 2017;3(2):118. doi: 10.4172/24719323.1000118

104. Rajput R. Improvement in Hair Loss and Better Hair Quality with Vitamin Therapy in Monilethrix. J Cosmo Trichol. 2016;2(3): 113. doi: 10.4172/2471-9323.1000113

105. Rajput R. Hair Loss due to Electromagnetic Radiation from Overuse of Cell Phone. J Cosmo Trichol. 2016;2:114.

106. Rajput RJ. Controlled clinical trial for evaluation of hair growth with low dose cyclical nutrition therapy in men and women without the use of finasteride. Plast Aesthet Res. 2017;4:161-173. 